\title{
Subthalamic Neurons Coordinate Basal Ganglia Function through Differential Neural Pathways
}

\author{
Yasunobu Yasoshima, ${ }^{1}$ Nobuyuki Kai, ${ }^{1}$ Shigetaka Yoshida, ${ }^{3}$ Sadao Shiosaka, ${ }^{4}$ Yoshimasa Koyama, ${ }^{5}$ Yukihiko Kayama, ${ }^{2}$ \\ and Kazuto Kobayashi ${ }^{1}$ \\ ${ }^{1}$ Department of Molecular Genetics, Institute of Biomedical Sciences, and 2Department of Physiology, Fukushima Medical University School of Medicine, \\ Fukushima 960-1295, Japan, ${ }^{3}$ Department of Anatomy, Asahikawa Medical College, Asahikawa 78-8510, Japan, ${ }^{4}$ Department of Structural Cellular Biology, \\ Nara Institute of Science and Technology, Ikoma 606-8501, Japan, and ${ }^{5}$ Department of Science and Technology, Fukushima University, Fukushima \\ 960-1296, Japan
}

The subthalamic nucleus (STN) is a key component of basal ganglia circuitry that mediates a variety of motor functions. The STN neurons send glutamatergic projections to the output structures of basal ganglia, including the substantia nigra pars reticulata ( $\mathrm{SNr}$ ) and the entopeduncular nucleus, and also innervate the globus pallidus (GP). However, the mechanism by which the STN regulates motor functions in the neural circuitry is not fully understood. Here we performed conditional ablation of the STN neurons by using immunotoxin-mediated cell targeting. We then analyzed dopamine (DA)-mediated motor behavior and firing activity of the SNr and GP neurons. Ablation of the STN neurons increased spontaneous movement and reduced hyperactivity in response to DA stimulation. Ablation of these neurons modulated the pattern and rate of spontaneous firing of the SNr neurons, although it did not substantially affect spontaneous firing of the GP neurons. The ablation attenuated DA-induced suppression of the firing rate of the SNr neurons and inhibited DA-induced elevation of the rate of the GP neurons. In addition, pharmacological blockade of GP activation in response to DA stimulation inhibited the suppression of SNr activity and the resultant motor activation. These results suggest that the STN neurons suppress spontaneous behavior through their direct projection to the output neurons and that, in response to DA, they contribute to expression of behavior by acting on the output neurons mainly through the GP-mediated pathways. We conclude that the STN coordinates motor behavior through differential neural pathways depending on the state of DA transmission.

Key words: dopamine; motor control; basal ganglia; subthalamic nucleus; firing activity; immunotoxin-mediated cell targeting

\section{Introduction}

The subthalamic nucleus (STN) is a component in the basal ganglia circuitry that mediates a variety of motor functions (Alexander and Crutcher, 1990; DeLong, 1990; Parent and Hazrati, 1995; Gerfen and Wilson, 1996). Accumulating evidence indicates that the STN plays important roles in movement control, behavioral performance, and motivational process (Hamada and DeLong, 1992a; Baunez et al., 1995, 2002; Baunez and Robbins, 1997; Dybdal and Gale, 2000). In addition, modulation of the STN activity is implicated in the motor symptoms in Parkinson's disease and in animal models with experimentally induced parkinsonism (Bergman et al., 1994; Hassani et al., 1996; Magnin et

Received Dec. 17, 2004; revised July 13, 2005; accepted July 14, 2005.

This work was supported by the following: grants-in aid from the Ministry of Education, Science, Culture, and Sports of Japan; Solution Oriented Research for Science and Technology and Research Institute of Science and Technology for Society of Japan Science and Technology Corporation; Toray Science Foundation; and Uehara Memorial Research Foundation. We thank Dr. I. Pastan for providing anti-Tac(Fv)-PE38 immunotoxin, Dr. K. Iseki for immunohistochemistry, R. Fukabori for vector construction, and Y. Takano, M. Kikuchi, and T. Kobayashi for technical support in animal experiments. We are also grateful to Drs. M. Takada, A. Nambu, and W.-J. Song for critical reading of this manuscript.

Correspondence should be addressed to Dr. Kazuto Kobayashi, Department of Molecular Genetics, Institute of Biomedical Sciences, Fukushima Medical University School of Medicine, Fukushima 960-1295, Japan. E-mail: kazuto@fmu.ac.jp.

DOI:10.1523/JNEUROSCI.1904-05.2005

Copyright $\odot 2005$ Society for Neuroscience $\quad$ 0270-6474/05/257743-11\$15.00/0 al., 2000). Lesion or high-frequency stimulation of the STN improves these motor symptoms (Bergman et al., 1990; Benazzouz et al., 1993; Witchmann et al., 1994; Limousin et al., 1995; Levy et al., 2000). The STN is thus a promising target for the surgical therapy of Parkinson's disease.

The output structures of the basal ganglia, including the substantia nigra pars reticulata $(\mathrm{SNr})$ and entopeduncular nucleus $(\mathrm{EPN})$, act as the interface of motor functions through their GABAergic inhibition of target brain regions. The STN neurons receive glutamatergic inputs from many cortical areas and GABAergic inputs from the globus pallidus (GP) (Smith et al., 1990; Bevan et al., 1997; Maurice et al., 1998; Nambu et al., 2000). These neurons send glutamatergic projections to the $\mathrm{SNr}$ and the EPN and also innervate the GP through their axonal collaterals (Kita et al., 1983; Kita and Kitai, 1987; Robledo and Féger, 1990; Nakanishi et al., 1991; Sato et al., 2000b). The GP neurons provide GABAergic inhibition to the $\mathrm{SNr}$ and the EPN (Bevan et al., 1997; Sato et al., 2000a). A standard model of the basal ganglia circuitry suggests that the direct projection from the STN to the output structures plays a major role in the regulation of motor functions (Alexander and Crutcher, 1990; DeLong, 1990; Parent and Hazrati, 1995; Gerfen and Wilson, 1996). In addition, recent evidence suggests that reciprocal connections between the STN and the GP generate network rhythmicity (Plenz and Kitai, 1999) 
and that changes in the rhythmicity may be involved in normal movement and pathological feature of movement disorders (Bevan et al., 2002). The mechanism by which the STN neurons regulate motor functions in the basal ganglia circuitry, however, is not fully understood.

In the present study, we perform conditional ablation of the STN neurons by using immunotoxin-mediated cell targeting (IMCT), which is a transgenic technique to eliminate specific cell types from a complex neural circuitry (Kobayashi et al., 1995; Watanabe et al., 1998; Sano et al., 2003). Then we examine the motor behavior dependent on dopamine (DA) transmission and analyze the firing activity of neurons that mediate the behavior in the basal ganglia circuitry. Our results provide evidence that the STN neurons act to coordinate basal ganglia function through differential neural pathways dependent on the state of DA transmission.

\section{Materials and Methods}

Generation of mutant mice. In the strategy of IMCT (Kobayashi et al., 1995), transgenic ( $\mathrm{Tg}$ ) mice are generated that express the human interleukin- 2 receptor $\alpha$-subunit (IL-2R $\alpha$ ) under the control of a cell type-specific promoter. These mice are then treated with a recombinant immunotoxin (IT), which is composed of the variable regions of the anti-IL-2R $\alpha$ monoclonal antibody and a bacterial exotoxin fragment. The transgene construct contained a $10 \mathrm{~kb}$ DNA fragment encoding the $5^{\prime}$-flanking region of the mouse neuropsin (NP) gene (Hirata et al., 2001 ), the second intron of the rabbit $\beta$-globin gene (Kobayashi et al., 1992), the gene cassette encoding IL-2R $\alpha$ fused to green fluorescent protein (IL-2R $\alpha / \mathrm{GFP}$ ) (Watanabe et al., 1998), and the polyadenylation signals of the rabbit $\beta$-globin gene and simian virus 40 early gene (Kobayashi et al., 1992). The construct was microinjected into fertilized mouse eggs, which were then implanted into pseudopregnant females. Tg mice were identified by Southern blot hybridization or PCR with genomic DNA prepared from tail clips. We produced six independent Tg lines, in which the high-level expression of the transgene was observed in the STN neurons. In the present study, we used one Tg line termed NP-IL-2R $\alpha /$ GFP3-5. Animal care and handling procedures were in accordance with the guidelines established by the Experimental Animal Center of Fukushima Medical University.

Intracranial injection. Mice (12-16 weeks old) were anesthetized with sodium pentobarbital $(50 \mathrm{mg} / \mathrm{kg}$, i.p.) and subjected to unilateral or bilateral treatment. For IT injection, anti-Tac(Fv)-PE38 (Kreitman et al., 1994) was diluted into a final concentration of $10 \mu \mathrm{g} / \mathrm{ml}$ in PBS containing $0.1 \%$ mouse albumin. The IT solution or PBS $(0.3 \mu \mathrm{l} / \mathrm{site})$ was injected into the STN through a glass microinjection capillary, which was surgically introduced by using the following coordinates (in $\mathrm{mm}$ ): anteroposterior, -2.10 ; mediolateral, 1.50; and dorsoventral, 4.60 from bregma and dura according to an atlas of the mouse brain (Paxinos and Franklin, 2001). Injection was performed at a constant velocity of 0.1 $\mu \mathrm{l} / \mathrm{min}$ with a microinfusion pump. In all experiments conducted in this study, the mice were used on day 7 after the IT injection (day 0 ). After the experiments, the brains were taken, and their sections were stained with neutral red. This staining confirmed the loss of the STN neurons in almost all of the IT-injected Tg mice.

For intrapallidal infusion of 2,3-dioxo-6-nitro-1,2,3,4- tetrahydro [f] quinoxaline-7-sulfonamide (NBQX), solution ( $0.25 \mu \mathrm{l} /$ site) was injected into the GP through a 33 gauge stainless steel cannula by using the following coordinates (in $\mathrm{mm}$ ): anteroposterior, -0.34 ; mediolateral, 1.80; and dorsoventral, 3.10 from bregma and dura. Administration was performed with a microinfusion pump. After the experiments, the placement of the tips of the cannula was confirmed by histological examination with neutral red staining.

Histological analysis. Mice were anesthetized with sodium pentobarbital and perfused transcardially with $4 \%$ paraformaldehyde in $0.1 \mathrm{M}$ phosphate buffer (PB), pH 7.4. Fixed brains were cut into sections $(30 \mu \mathrm{m}$ thick) through the coronal plane with a cryostat. Free-floating sections were stained with neutral red. For immunohistochemistry (Sano et al.,
2003), sections were incubated with primary antibodies against neuronspecific nuclear protein (NeuN) (1:500 dilution; Chemicon, Temecula, CA), glial fibrillary acidic protein (GFAP) (1:500 dilution; LipshawImmunon, Pittsburgh, PA), tyrosine hydroxylase (TH) $(0.4 \mu \mathrm{g} / \mathrm{ml}$; Roche, Basel, Switzerland), and c-fos (1:5000 dilution; Santa Cruz Biotechnology, Santa Cruz, CA). The sections were incubated with biotinylated secondary antibodies at 1:1000 dilution and visualized with a Vectastain Elite ABC kit (Vector Laboratories, Burlingame, CA).

For cell counting, sections through the STN at the anteroposterior coordinates from bregma between -1.70 and $-2.18 \mathrm{~mm}$ were stained with neutral red. Sections through the GP at the anteroposterior coordinates from bregma between -1.70 and $-2.18 \mathrm{~mm}$ were immunostained with anti-c-fos antibody. Fifteen to 20 sections from each animal were used. The number of stained cells was counted with a computer-assisted imaging program (NIH Image 1.62; National Institutes of Health, Bethesda, MD). The average of the values obtained from each animal was calculated.

For in situ hybridization (Sano et al., 2003), fresh-frozen brain sections (10 $\mu \mathrm{m}$ thick) were fixed in a solution of $4 \%$ paraformaldehyde in $0.1 \mathrm{M}$ $\mathrm{PB}$ and treated with $0.1 \mathrm{M}$ triethanolamine, $\mathrm{pH} 8.0$, containing $0.25 \%$ acetic anhydride. The sections were hybridized with antisense RNA probes for mouse $\mathrm{DA}_{1}$ or $\mathrm{D}_{2}$ receptors labeled by using in vitro transcription with digoxigenin-11-UTP (Roche). The hybridized signals were visualized with a nonradioactive detection system using antidigoxigenin Fab fragments conjugated to alkaline phosphatase (Roche).

Neurochemical analysis. Contents of DA and its metabolites 3,4dihydroxy-phenylacetic acid (DOPAC) and homovanillic acid (HVA) were measured by using a HPLC equipped with an electrochemical detection system (Kobayashi et al., 1994). Tissues were homogenized in $5 \mathrm{vol}$ of $0.2 \mathrm{M}$ perchloric acid containing $0.1 \mathrm{M}$ EDTA and $100 \mathrm{ng} / \mathrm{ml}$ isoproterenol. The mobile phase was $0.1 \mathrm{M}$ sodium citrate, $0.1 \mathrm{M}$ citric acid, $0.5 \mathrm{~mm}$ sodium octanesulfonate, $0.15 \mathrm{~mm}$ EDTA, and $12 \%$ methanol, pH 3.5.

Behavioral analysis. Locomotor activity was measured with a movement analyzer equipped with photobeam sensors (Nishii et al., 1998). The number of beam breaks was counted for every $10 \mathrm{~min}$ period (movement score). The total number of beam breaks in a 30 min test period was calculated to evaluate spontaneous locomotor activity during the pretreatment $(-40$ to $-10 \mathrm{~min})$ and drug-induced locomotor activity after drug treatment (10-40 $\mathrm{min})$.

For rotational behavior, mice were placed in a spherical bowl $(25 \mathrm{~cm}$ diameter), and their behavior was monitored with a digital video camera. One rotation was defined as a complete $360^{\circ}$ turn. The total number of rotations in a $30 \mathrm{~min}$ test period was counted to evaluate spontaneous rotations during the pretreatment $(-40$ to $-10 \mathrm{~min})$ and druginduced rotations after drug treatment (20-50 min).

Electrophysiological recording. Extracellular single-unit recording was performed according to the method used for recording of rat brain under the awake head-restraint condition (Koyama et al., 2003) with some modifications. Mice were anesthetized with sodium pentobarbital and surgically implanted with a U-shaped plastic plate on their skull. Four days after the surgery, the mice were placed in a plastic chamber, and the $\mathrm{U}$-shaped plastic plate was fixed to the stereotaxic apparatus. Single-unit activity was recorded through a glass pipette microelectrode (10-12 $\mathrm{M} \Omega$ at $1 \mathrm{kHz}$ ), amplified, and monitored with a digital oscilloscope. During single-unit recording, electroencephalograms were monitored to confirm the awake status of the mice. The recording data were processed by a computer system equipped with the Spike2 software (Cambridge Electronic Design, Cambridge, UK). The recording coordinates from the bregma and dura were as follows (in $\mathrm{mm}$ ): $\mathrm{SNr}$, anteroposterior, -3.80 to -2.80; mediolateral, 1.00-1.75; and dorsoventral, 3.80-5.30; GP, anteroposterior, -0.70 to -0.10 ; mediolateral, $1.50-2.10$; and dorsoventral, 3.30-4.80. The placement sites of microelectrodes were verified by Pontamine Sky Blue deposit counterstained with neutral red.

For off-line analysis of spontaneous firing activity, the interspike interval (ISI) histogram, autocorrelogram, and mean firing rate were calculated from at least 500 spikes or 2 min duration of units. Each unit was classified into different firing types according to the ISI histogram and 

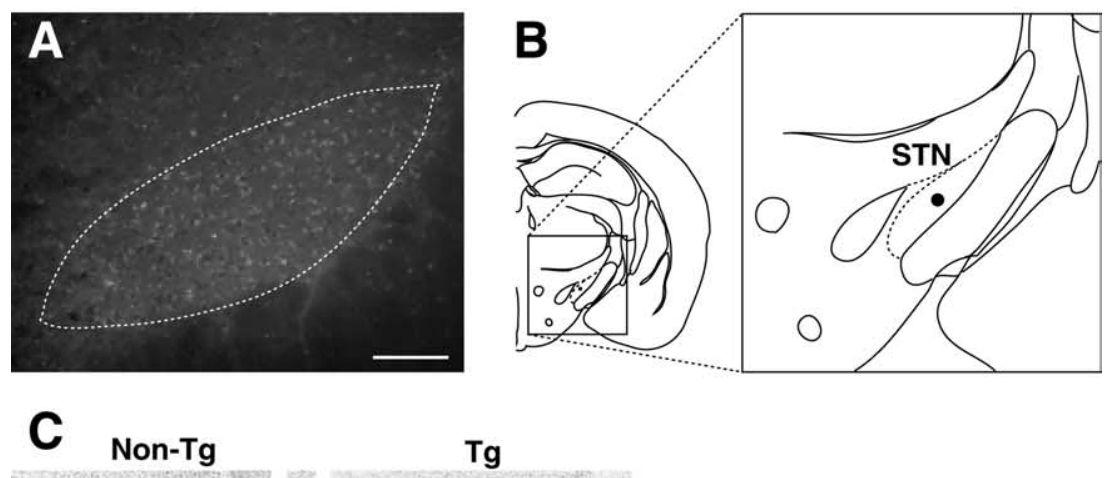

Tg
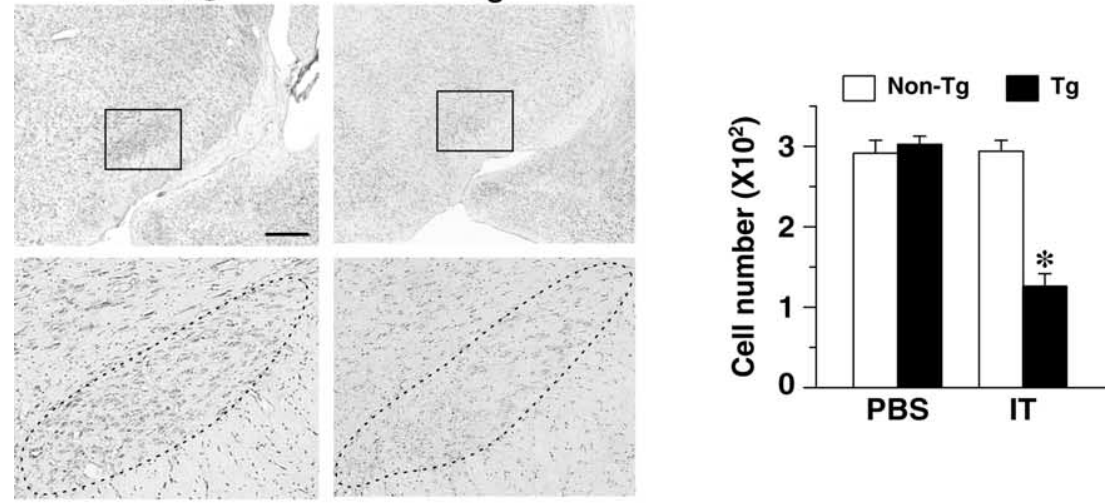

D Striatum
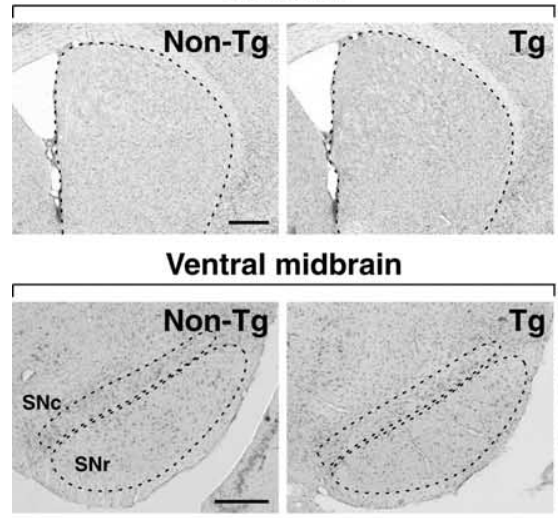

Tg

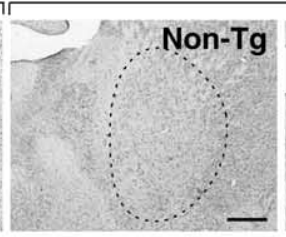

GP

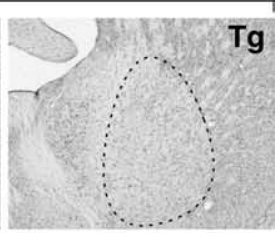

Thalamus

\section{E}

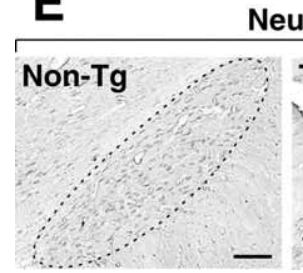

NeuN
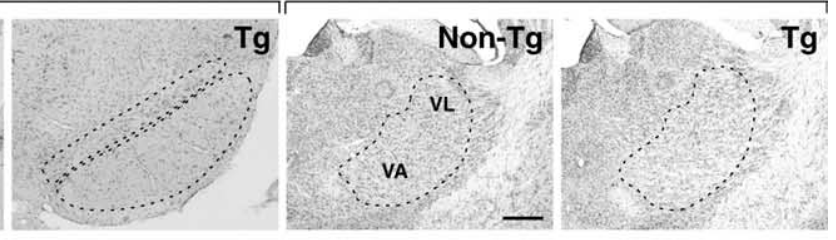

$\mathrm{Tg}$

Figure 1. Conditional ablation of STN neurons in NP-IL-2R $\alpha /$ GFP Tg mice. $A$, Fluorescence microscopic image of coronal sections through the STN in the Tg mice indicating expression of IL-2R $\alpha /$ GFP fusion gene in these neurons. $B$, Schematic illustration of the coordinate for the intrasubthalamic injection ( $-2.10 \mathrm{~mm}$ from bregma in the anteroposterior plane). Filled circle indicates the injection site. C, Neutral red staining of sections through the STN. Unilaterally injected mice $(n=5$ for non-Tg mice; $n=6$ for Tg mice) were used for the staining. The number of cells in the STN was counted by using a computer-assisted imaging program. ${ }^{*} p<0.001$, significant difference from the IT-injected non-Tg mice. Representative light microscopic images of the IT-injected side are indicated, and bottom images are 16-fold magnified views of the STN (boxes in the top images). D, Neutral red staining of sections through the striatum, GP, ventral midbrain, and thalamus. Unilaterally IT-injected mice were used for the staining, and light microscopic images of the injected side are indicated. SNC, Substantia nigra pars compacta; $V A$, ventral anterior thalamic nucleus; $V L$, ventrolateral thalamic nucleus. $\boldsymbol{E}$, Immunostaining for NeuN and GFAP of sections through the STN prepared from unilaterally IT-injected mice. Scale bars: $A, E, 100 \mu \mathrm{m} ; C, 400$ $\mu \mathrm{m} ; \boldsymbol{D}, 200 \mu \mathrm{m}$. autocorrelogram as described previously (Ni et al., 2000). In brief, the regular type was characterized by a symmetrical distribution of ISI and an autocorrelogram showing at least three identifiable peaks. The irregular type was characterized by an asymmetrical distribution of ISI and an autocorrelogram with less than two peaks. The bursty type was characterized by the appearance of bursts separated by the absence of discharge or by lowfrequency tonic activity, showing an asymmetrical or random distribution of ISI and an autocorrelogram without peak or with a single initial peak. Classification of the bursty firing was confirmed by using the computer algorithms described by Kaneoke and Vitek (1996).

Statistical analysis. The ANOVA and the post hoc Tukey's test were used for statistical comparisons. All values were expressed as the mean \pm SEM of the data.

\section{Results}

\section{Conditional ablation of STN neurons} by IMCT

We produced Tg mice that carry the IL-2R $\alpha$ / GFP gene cassette downstream of the $5^{\prime}$ flanking region of the gene encoding NP, which is a serine protease expressed in the brain (Hirata et al., 2001). The NP-IL-2R $\alpha$ / GFP mice expressed the fusion protein in the majority of neurons in the STN (Fig. $1 A$ ). We unilaterally injected IT solution or PBS into the STN by using a stereotaxic approach (Fig. $1 B)$. The injected mice were subjected to brain sectioning, and the sections through the STN were stained with neutral red (Fig. $1 C$ ). On the IT-injected side, the number of the STN neurons in the Tg mice was markedly decreased to $35 \%$ of that in the non-Tg mice $(p<0.001)$, whereas the cell number on the PBS-injected side was not significantly different between the two kinds of mice. The sections through the striatum, GP, ventral midbrain, and thalamus were also stained with neutral red, and there was no apparent damage to these brain regions on the IT-injected side of the Tg mice (Fig. 1D). In addition, we performed immunohistochemistry for the neuronal marker NeuN and the glial marker GFAP. The number of NeuN-positive cells in the STN of the Tg mice was remarkably decreased relative to that of the non- $\mathrm{Tg}$ mice (Fig. 1E). There were few GFAP-positive signals in the STN of the non-Tg and Tg mice (Fig. $1 E$ ). These data indicate a selective and efficient elimination of the STN neurons in the $\mathrm{Tg}$ mice by the IT injection.

To examine the influence of the STN ablation on the midbrain DA system, we performed immunostaining with sections through the midbrain or the striatum prepared from unilaterally injected mice. The staining pattern of $\mathrm{TH}$-positive neurons and intensity of their immunoreactive signals in the ventral midbrain exhibited no visible changes on the IT-injected side in the Tg mice 
A

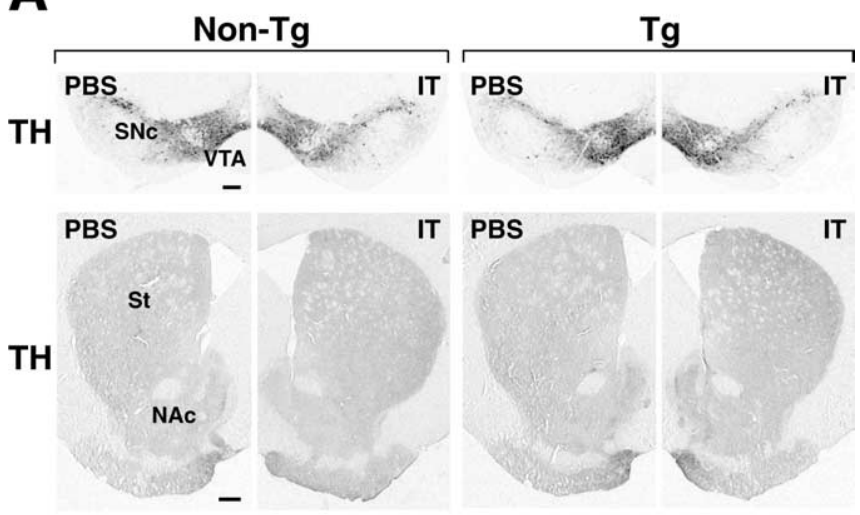

B

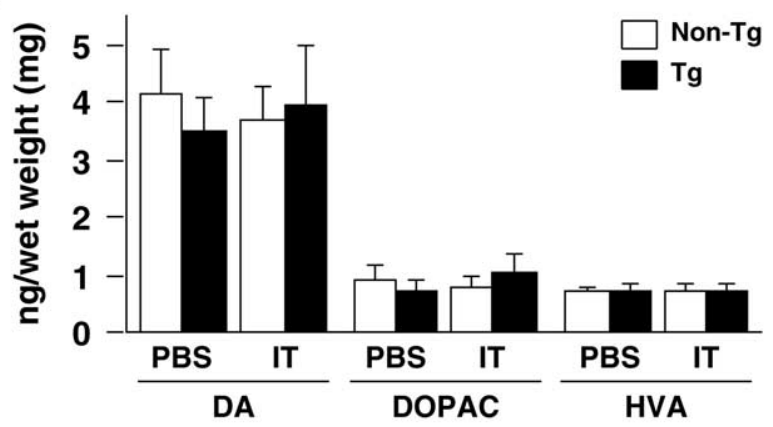

C
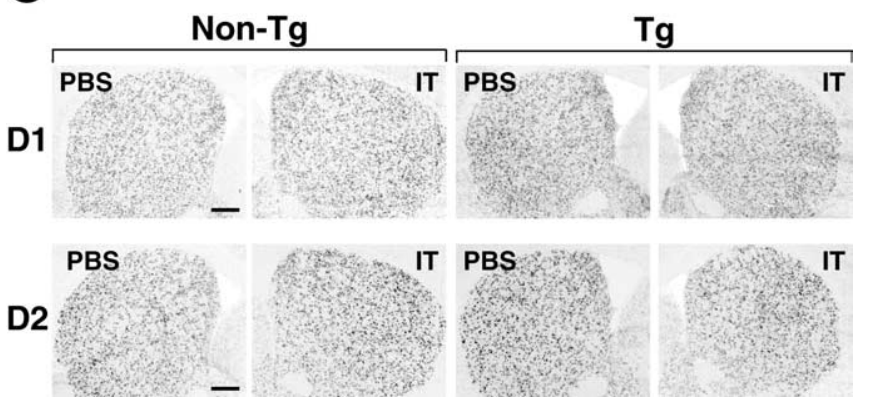

Figure 2. STN ablation does not influence midbrain DA system and DA receptor distribution. $\boldsymbol{A}$, TH immunostaining of sections through the midbrain or the striatum prepared from unilaterally injected mice. The substantia nigra pars compacta (SNc) and the ventral tegmental area (VTA) in the ventral midbrain are indicated. The dorsal striatum (St) and the nucleus accumbens (NAc) are indicated. $B$, Contents of DA, DOPAC, and HVA in the striatum dissected from unilaterally injected mice $(n=10)$. $C$, In situ hybridization analysis for $D A D_{1}$ and $D_{2}$ receptor mRNAs in the striatum. Sections prepared from unilaterally injected mice were used for in situ hybridization with digoxigenin-labeled antisense RNA probes. Scale bars, $200 \mu \mathrm{m}$.

compared with those for the PBS-injected Tg mice or the IT- or PBS-injected non-Tg mice (Fig. 2A). The distribution of THpositive fibers in the striatum on the IT-injected side of the $\mathrm{Tg}$ mice was also unaffected (Fig. $2 A$ ). In addition, we determined the contents of DA and its metabolites (DOPAC and HVA) in the striatum of unilaterally injected mice (Fig. $2 \mathrm{~B}$ ). Statistical analysis displayed no significant difference in the contents of DA, DOPAC, or HVA between the two injection sides or the two genotypes. Furthermore, we analyzed the gross distribution of DA receptors in the striatum by using in situ hybridization for DA $D_{1}$ or $D_{2}$ receptor mRNA. Patterns of hybridization signals indicated apparently normal distribution of these two receptors in the striatum on the IT-injected side of the Tg mice (Fig. 2C).
A B

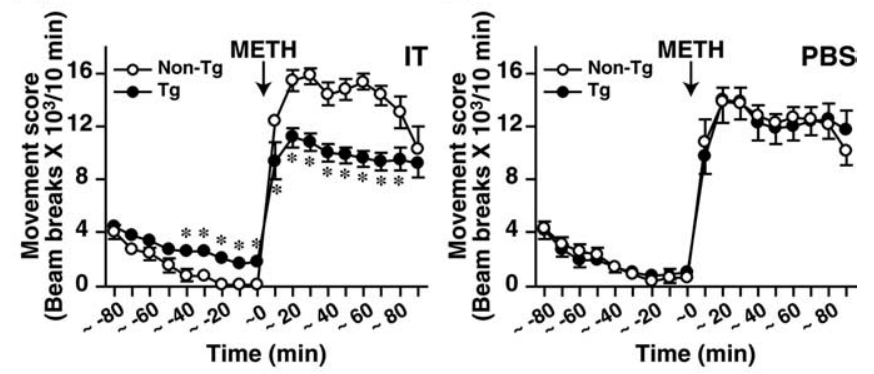

C

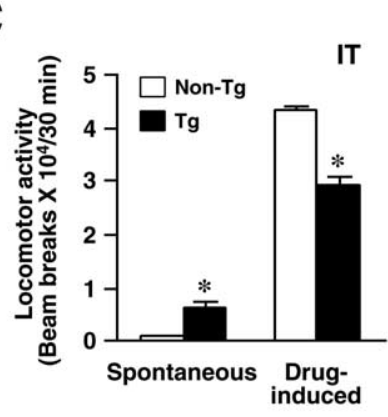

D

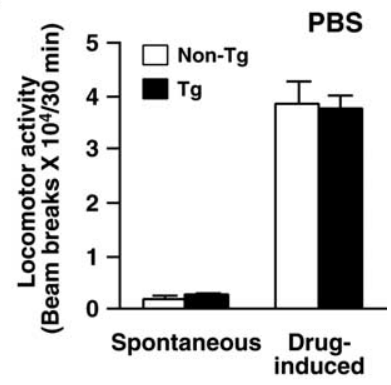

$\mathbf{E}$

$\mathbf{F}$
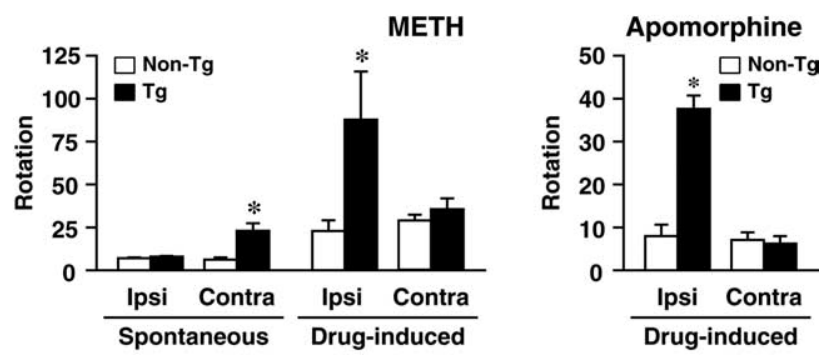

Figure 3. STN ablation causes abnormality in motor behavior. $\boldsymbol{A}, \boldsymbol{B}$, Time course of spontaneous and METH-induced locomotion. Mice $(n=6)$ were bilaterally injected with IT solution $(\boldsymbol{A})$ or PBS $(\boldsymbol{B})$ for the behavioral test. After monitoring of spontaneous movement, the mice were administered METH (4.0 mg/kg, s.c.). Movement score for every 10 min was counted. ${ }^{*} p<0.05$, significant differences from non-Tg mice. $\boldsymbol{C}, \boldsymbol{D}$, Locomotor activity. The total number of beam breaks in a 30 min test period was calculated to evaluate spontaneous locomotor activity during the pretreatment ( -40 to $-10 \mathrm{~min}$ ) and METH-induced locomotor activity after treatment (10 - $40 \mathrm{~min}$ ). Locomotor activity of IT-injected $(\boldsymbol{C})$ and PBS-injected $(\boldsymbol{D})$ mice is shown. ${ }^{*} p<0.01$, significant differences from non-Tg mice. $\boldsymbol{E}, \boldsymbol{F}$, Rotational behavior. Mice $(n=6)$ were unilaterally injected with IT solution for the behavioral test. After monitoring of spontaneous rotations, the mice were administered METH ( $4.0 \mathrm{mg} / \mathrm{kg}$, s.c.) $(\boldsymbol{E})$ or apomorphine $(2.0 \mathrm{mg} / \mathrm{kg}$, s.c.) $(\boldsymbol{F})$. The total number of contralateral or ipsilateral rotations in a $30 \mathrm{~min}$ test period was calculated to evaluate spontaneous rotations during the pretreatment ( -40 to $-10 \mathrm{~min}$ ) and drug-induced rotations after drug administration (20-50 min). ${ }^{*} p<0.05$, significant differences from non-Tg mice.

\section{Ablation of STN neurons disturbs DA-mediated motor behavior}

Systemic administration of drugs that stimulate DA receptors is known to induce hyperactivity in movement. To assess the consequence of the STN ablation in motor behavior, we bilaterally injected IT solution and monitored locomotor activity in the open field (Fig. $3 A, C$ ). Spontaneous locomotor activity in the $\mathrm{Tg}$ mice was significantly increased relative to that in the non- $\mathrm{Tg}$ mice, and the increase was 6.5-fold $(p<0.01)$. After administration of methamphetamine (METH) $(4.0 \mathrm{mg} / \mathrm{kg}$, s.c.), which stimulates DA release from presynaptic terminals, METHinduced locomotor activity in the non- $\mathrm{Tg}$ mice exhibited a 43fold increase relative to their spontaneous activity. In contrast, 
METH-induced locomotor activity in the Tg mice was 5.1-fold higher than their spontaneous activity, and it was significantly lower than the corresponding value of the non-Tg mice $(68 \%$; $p<0.01)$. Mice of the two genotypes that received a bilateral sham operation with PBS displayed similar spontaneous and METH-induced locomotor activity (Fig. $3 B, D$ ). These data indicate that ablation of the STN neurons caused an increase in spontaneous movement and that it reduced the hyperactivity in response to systemic DA stimulation.

To further assess the behavioral consequence of the STN ablation, we unilaterally injected IT solution and tested the rotational behavior. As shown in Figure $3 E$, the injected Tg mice displayed spontaneous rotations in the direction contralateral to the injected side. After treatment with METH (4.0 mg/kg, s.c.), the $\mathrm{Tg}$ mice reversed their rotations in the ipsilateral direction. However, the injected non-Tg mice showed neither spontaneous nor drug-induced rotations. In addition, treatment with apomorphine $(2.0 \mathrm{mg} / \mathrm{kg}$, s.c.), which is a nonselective DA receptor agonist, induced the ipsilateral rotations in unilaterally ITinjected Tg mice (Fig. $3 F$ ). These data suggest that the unilateral IT injection caused hyperactivity in spontaneous movement on the injected side relative to the intact side and that, in response to DA stimulation, it produced a reduction in motor activation in the injected side relative to the intact side. The data are consistent with the results obtained from the assessment of locomotor activity showing that the STN ablation increased spontaneous movement and reduced the DA-induced hyperactivity.

STN ablation alters spontaneous firing of the output neurons To examine the influence of STN ablation on the firing activity of the output neurons, we performed extracellular single-unit recording of the activity of the SNr neurons. Previous electrophysiological studies show that these neurons are divided into several types with different firing patterns (Burbaud et al., 1995; Murer et al., 1997). We unilaterally injected PBS or IT into the STN and recorded the firing activity of units by using microelectrodes placed within the SNr (Fig. 4A). To evaluate the pattern of spontaneous firing, we analyzed the ISI histogram and the autocorrelogram of each unit and categorized the units into three different types: regular, irregular, and bursty. Typical firing patterns obtained from the IT-injected side are shown in Figure 5. The proportion of units belonging to each type on the PBS-injected side was indistinguishable between the non- $\mathrm{Tg}$ and $\mathrm{Tg}$ mice, whereas the proportion on the IT-injected side was different between the two genotypes $(p<0.001)$ (Fig. $4 B)$. On the IT-injected side of the $\mathrm{Tg}$ mice, the proportion of the regular type was reduced, whereas that of the bursty type was increased. In addition, the mean firing rate of each type on the PBS-injected side was indistinguishable between the two genotypes, whereas the rate of the regular type on the IT-injected side was markedly reduced in the $\mathrm{Tg}$ mice relative to that of the non-Tg mice $(p<0.05)$, and the rate of other types tended to decrease in the Tg mice (Fig. 4C). On the IT-injected side, the mean firing rate of the total units in the $\mathrm{Tg}$ mice was $62 \%$ of that in the non-Tg mice $(p<0.05)$ (Fig. $4 C)$. Therefore, the STN ablation shifted the pattern of spontaneous firing of the $\mathrm{SNr}$ neurons and reduced the firing rate of these neurons, although the rate reduction was evident in the regular-type neurons.

\section{STN ablation does not influence spontaneous firing of the GP neurons}

A previous study of single-unit recording of GP neurons indicates the presence of some neuronal types with different firing patterns
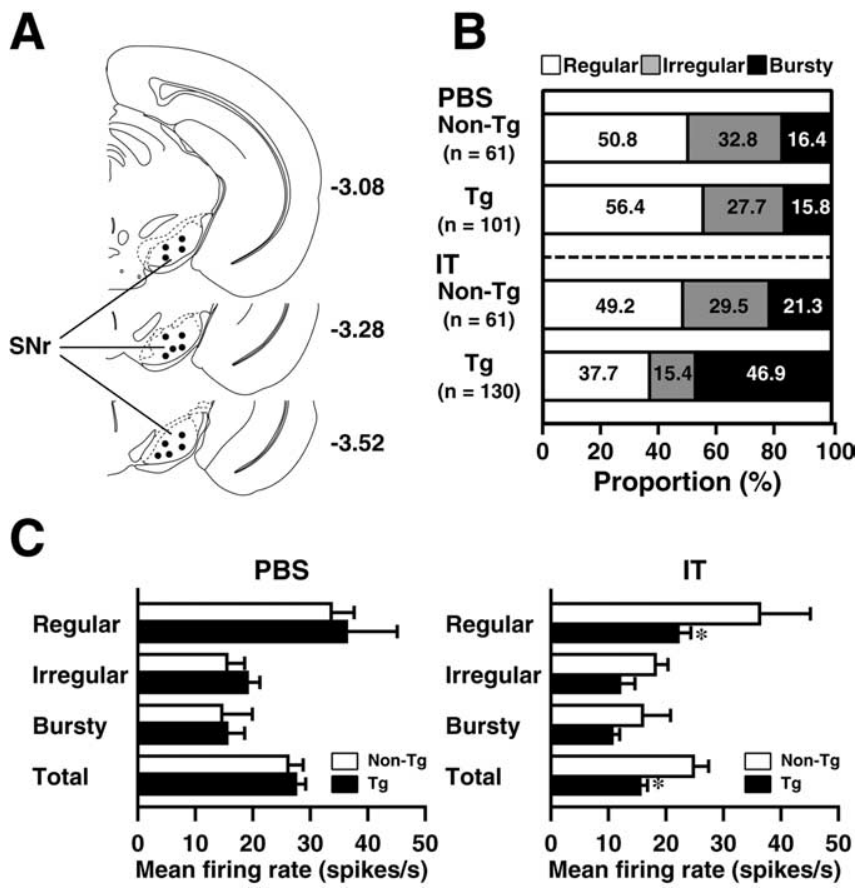

Figure 4. STN ablation alters spontaneous firing of the SNr neurons. Unilaterally injected mice were used for extracellular single-unit recording of firing activity. $\boldsymbol{A}$, Schematic illustration of representative microelectrode placement sites within the SNr. Number indicates the distance (in millimeters) from bregma in the anteroposterior plane. $\boldsymbol{B}$, Proportion of the three firing types. Number of units recorded from four to eight mice is shown in parentheses. C, Spontaneous mean firing rate of the three firing types and total units on the PBS- or IT-injected side. ${ }^{*} p<$ 0.05 , significant difference from non-Tg mice.

(Ni et al., 2000). We analyzed the pattern and the rate of spontaneous firing of the GP neurons. Unilaterally IT-injected mice were subjected to single-unit recording by using microelectrodes placed within the GP (Fig. 6A). According to the procedure used for unit recording of the $\mathrm{SNr}$ neurons, the pattern of spontaneous firing of the GP neurons was divided into the irregular and bursty types. The proportion of the irregular and the bursty types in non-Tg mice was similar to that in the Tg mice (Fig. $6 \mathrm{~B}$ ), and the mean firing rate of each type was indistinguishable between the non-Tg and Tg mice (Fig. 6C). Thus, the STN ablation did not substantially alter spontaneous firing activity of the GP neurons.

\section{STN elimination attenuates DA-induced regulation of the output neuron activity}

Systemic administration of METH is reported to suppress the firing activity of the SNr neurons (Gulley et al., 1999). Our preliminary experiment using single-unit recording indicated that METH administration suppressed the firing rate of three different types of the SNr neurons (data not shown). To examine the influence of STN elimination on METH-induced firing activity of the output neurons, we recorded single-unit activity of the $\mathrm{SNr}$ neurons from unilaterally IT-injected mice and administered METH (1.0 mg/kg, s.c.) (Fig. 7A). The ratio of METH-induced firing rate relative to spontaneous firing rate in each unit was evaluated (Fig. $7 B$ ). In the non-Tg mice, the ratio of the firing rate was gradually decreased after METH administration. In the $\mathrm{Tg}$ mice, the ratio was also decreased after the drug administration, but the extent of decrease became moderate at the late phase (20-25 min after administration) relative to that in the non- $\mathrm{Tg}$ mice $(p<0.05 ; p<0.01)$. These data show that the STN elimi- 
nation attenuated suppression of the firing rate of $\mathrm{SNr}$ neurons in response to METH.

STN elimination blocks DA-induced regulation of the GP neuron activity Systemic administration of drugs that stimulate DA receptors is reported to increase the firing activity of GP neurons (Zhang et al., 1998). We analyzed METHinduced firing activity of the GP neurons in the STN-ablated mice (Fig. 8 A). Singleunit activity was recorded from the burstytype GP neurons. The ratio of METHinduced firing rate relative to spontaneous firing rate was evaluated (Fig. $8 \mathrm{~B}$ ). In the non-Tg mice, the ratio of the firing rate was gradually increased after the METH administration. In the Tg mice, however, the ratio was sustained at a value similar to the spontaneous firing rate even after the drug administration $(p<0.05)$. Therefore, the STN elimination blocked elevation of the firing of the GP neurons in response to METH.

\section{Pharmacological blockade of the GP activation inhibits DA response of the output neuron activity and motor behavior}

The results obtained from single-unit recording of METH-induced firing activity of the SNr and GP neurons suggest that ablation of the STN neurons, through the blockade of drug-induced activation of the GP neurons, attenuated the suppression of the $\mathrm{SNr}$ activity. If this possibility is indeed the case, a pharmacological blockade of glutamatergic excitation of the GP neurons would be expected to inhibit METHinduced suppression of the $\mathrm{SNr}$ neurons. We thus tested the efficacy of intrapallidal treatment with an AMPA receptor antagonist, NBQX, on METH-induced firing activity of these neurons. C57BL/6J inbred mice received intrapallidal treatment with NBQX (125 ng/site) or PBS and administered METH before single-unit recording of the SNr neurons. As shown in Figure $9 A$, NBQX inhibited METH-induced suppression of the firing rate of the $\mathrm{SNr}$ neurons, and this inhibition was evident at the late phase $(p<0.05 ; p<0.01)$. To confirm whether the intrapallidal treatment with NBQX altered GP activation in response to METH, we performed immunostaining for the immediate-early gene c-fos, which is a marker of cellular responsiveness (Cenci et al., 1992; Ruskin and Marshall, 1995). The inbred mice were treated intrapallidally with NBQX or PBS and administered METH before brain sectioning. The sections through the GP were immunostained with anti-c-fos antibody (Fig. 9B). Many c-fos-positive cells were observed in the GP in the PBS-treated group, whereas the number of immunopositive cells in the NBQX-treated group was markedly decreased relative to that in the PBS-treated group

\section{Irregular}

\section{Bursty}

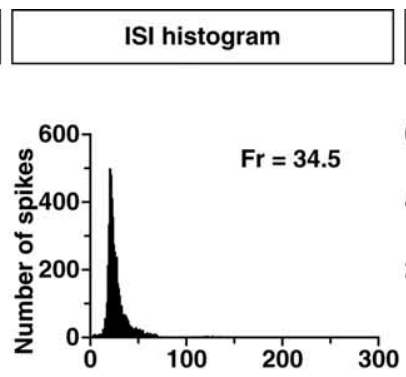

Autocorrelogram
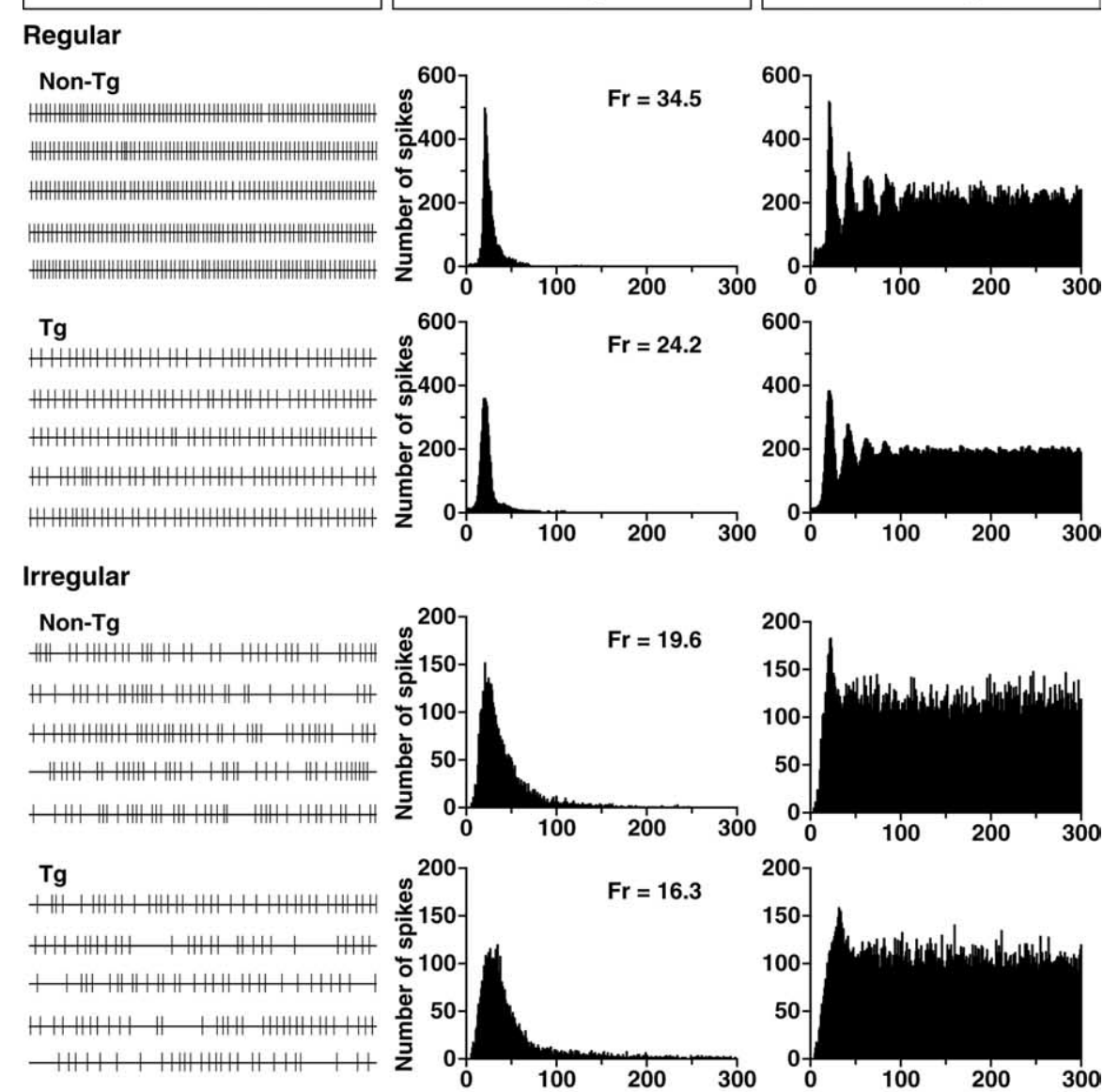

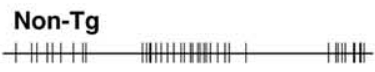

+
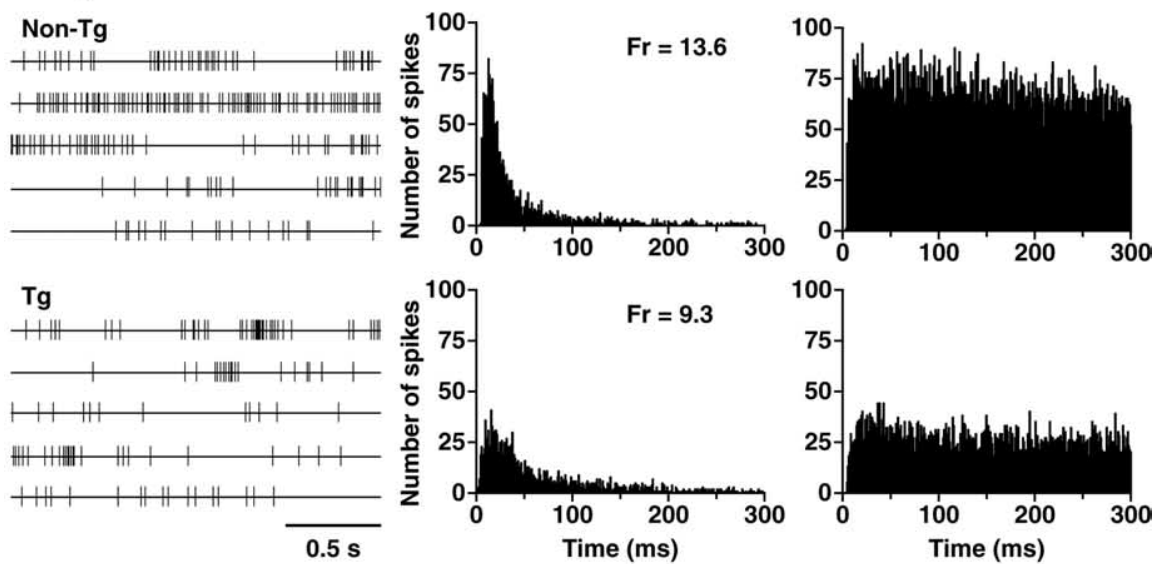

Figure 5. Firing pattern of the SNr neurons. The digital raster display, ISI histogram, and autocorrelogram of the typical firing types (regular, irregular, and bursty) obtained from the IT-injected side of non-Tg and Tg mice are shown. The mean firing rate (Fr; spikes per second) of the unit is presented in the ISI histogram.

$(58 \% ; p<0.05)$. The data indicate that the intrapallidal treatment with NBQX indeed inhibited METH-induced activation of the GP neurons. These results support the view that the STN ablation influences METH-induced suppression of the SNr activity by blockading GP activation.

In addition, we explored whether the blockade of glutamatergic GP activation could diminish METH-induced hyperactivity in movement. Mice were treated intrapallidally with different doses of NBQX and administered METH for locomotion analysis (Fig. 9C). METH-induced locomotor activity in the NBQX- 
A $-0.34$

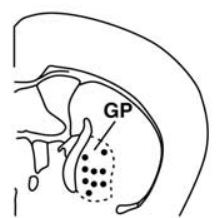

$-0.58$

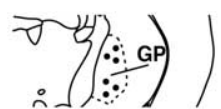

$-0.70$

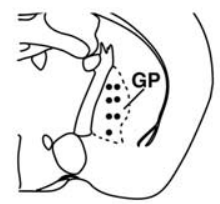

B

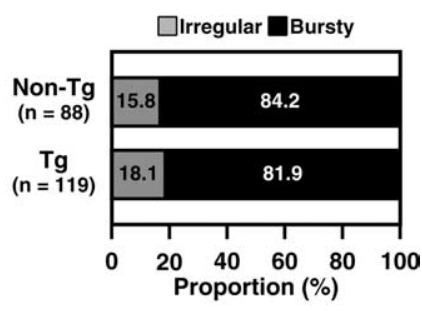

C

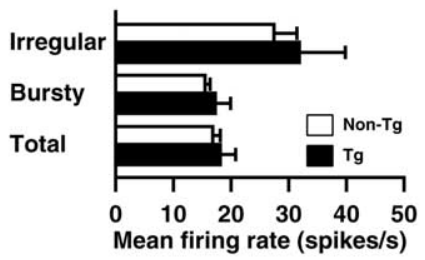

Figure 6. STN ablation does not change spontaneous firing of the GP neurons. Unilaterally IT-injected mice were used for single-unit recording of firing activity. The recording was performed from the injected side. $\boldsymbol{A}$, Schematic illustration of representative microelectrode placement sites within the GP. Number indicates the distance (in millimeters) from bregma in the anteroposterior plane. $\boldsymbol{B}$, Proportion of the firing types. Number of units recorded from eight mice is shown in parentheses. $C$, Spontaneous mean firing rate of the firing types and total units.

treated group was dose dependently decreased relative to that in the PBS-treated group $(p<0.05)$, and decreases were $33 \%$ at the lower dose (25 ng/site) and $42 \%$ at the higher dose (125 ng/site) of the control value. However, locomotor activity in the absence of METH administration was not altered by intrapallidal NBQX treatment (data not shown). These results indicate that the pharmacological blockade of the GP activity reduced the METHinduced hyperactivity.

\section{Activation of the STN neurons in response to systemic}

DA stimulation

Administration of drugs that stimulate DA receptors is known to increase the firing activity of the STN neurons (Kreiss et al., 1996, 1997). To ascertain whether systemic administration of METH induced activation of the STN activity, we examined METHinduced expression of $\mathrm{c}$-fos in the STN. C57BL/6J inbred mice were administered PBS or METH ( $4.0 \mathrm{mg} / \mathrm{kg}$, s.c.) and used for brain sectioning. The sections through the STN were immunostained with anti-c-fos antibody (Fig. 10). There were a number of c-fos-positive cells in the STN in the METH-administered group (106 \pm 10 cells per section; $n=4)$. These data support the previous reports that systemic DA stimulation activates the STN neurons (Kreiss et al., 1996, 1997).

\section{Discussion}

In the present study, we performed conditional ablation of the STN neurons from basal ganglia circuitry by using the IMCT technique. We then examined DA-mediated motor behavior and analyzed the firing activity of the SNr and GP neurons that normally receive the STN inputs. Ablation of the STN neurons caused an increase in spontaneous movement, whereas it reduced hyperactivity in response to METH stimulation. Ablation of these neurons also modulated the pattern and rate of spontaneous firing of the SNr neurons, although it did not substantially affect spontaneous firing of the GP neurons. The ablation attenuated $\mathrm{METH}$-induced suppression of the firing rate of the $\mathrm{SNr}$ neurons and inhibited METH-induced elevation of the firing rate of the GP neurons. In addition, pharmacological blockade of GP acti-

A

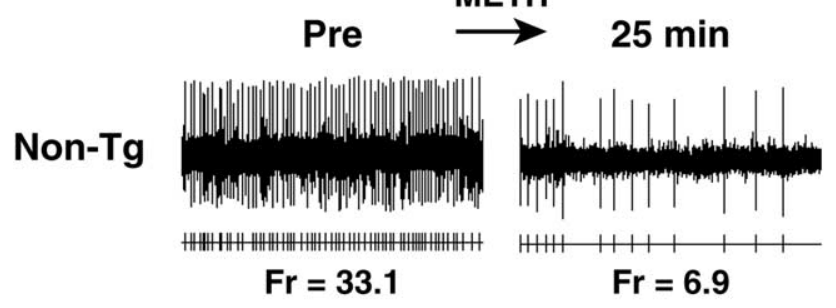

Tg

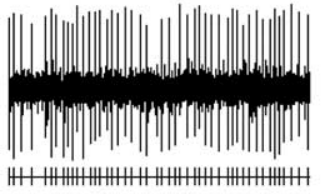

$\mathrm{Fr}=\mathbf{2 6 . 5}$

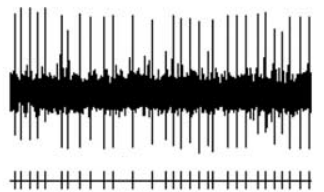

$\mathrm{Fr}=18.8$
$0.5 \mathrm{~s}$

B

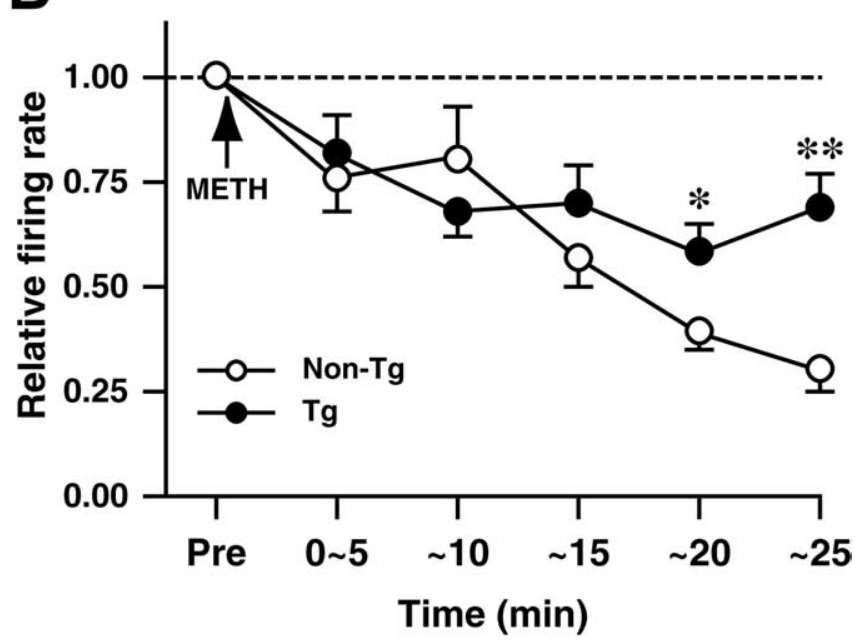

Figure 7. STN elimination attenuates METH-induced suppression of the SNr activity. $\boldsymbol{A}$, METH-induced firing of the SNr neurons. After recording of spontaneous firing, the mice were administered METH (1.0 mg/kg, s.c.), and recording was then performed from the IT-injected side. The firing pattern and digital raster display of representative units during pretreatment (Pre) and 25 min after treatment are shown. The mean firing rate ( $\mathrm{Fr}$; spikes per second) of the unit is presented. $\boldsymbol{B}$, Time course of METH-induced firing rate. The average of firing rate for every 5 min period was calculated, and the ratio of drug-induced firing rate relative to spontaneous firing rate was plotted $(n=11) .{ }^{*} p<0.05,{ }^{* *} p<0.01$, significant differences from non-Tg mice.

vation in response to METH stimulation inhibited the suppression of SNr activity and the resultant motor activation.

IMCT of the STN neurons caused spontaneous hyperactivity, which was accompanied by a shift in the pattern of spontaneous firing of the SNr neurons and a reduction in the rate of spontaneous firing of these neurons, while preserving the activity of the GP neurons (supplemental Fig. $1 A$, available at www.jneurosci. org as supplemental material). These results indicate a key role of the STN neurons in spontaneous motor behavior and spontaneous firing activity of the $\mathrm{SNr}$ neurons. The results suggest that the STN neurons normally act to maintain spontaneous firing of the SNr neurons predominantly through the direct subthalamonigral pathway, thereby suppressing spontaneous movement (supplemental Fig. $1 B$, available at www.jneurosci.org as supplemental material). These data support the standard model of basal ganglia circuitry that proposes a major role of the subthalamonigral pathway in suppression of motor functions (Alexander and 
A

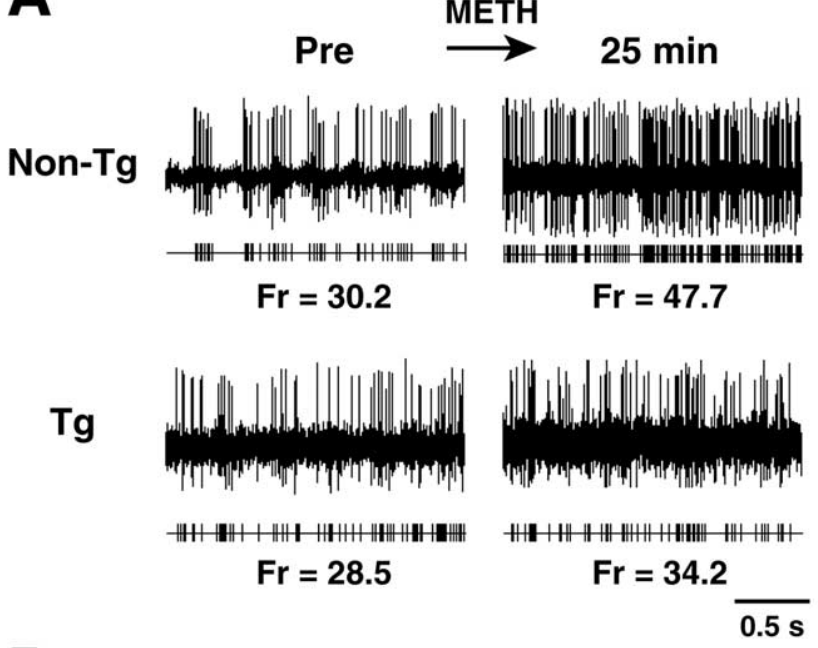

A

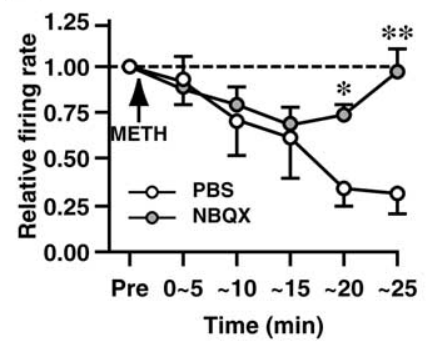

C

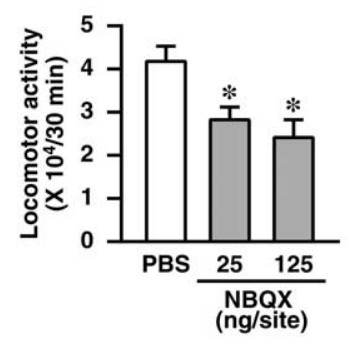

B
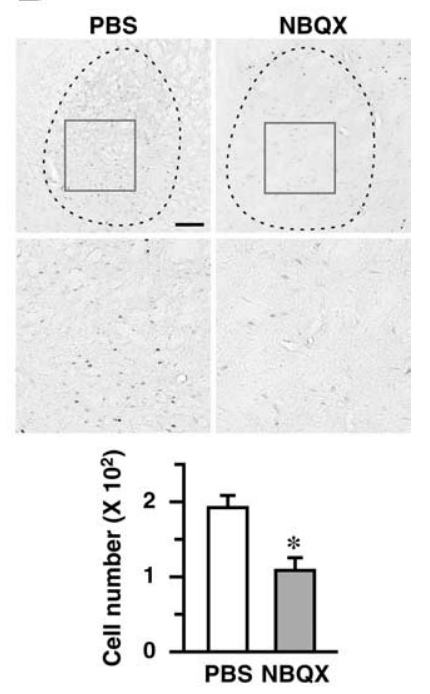

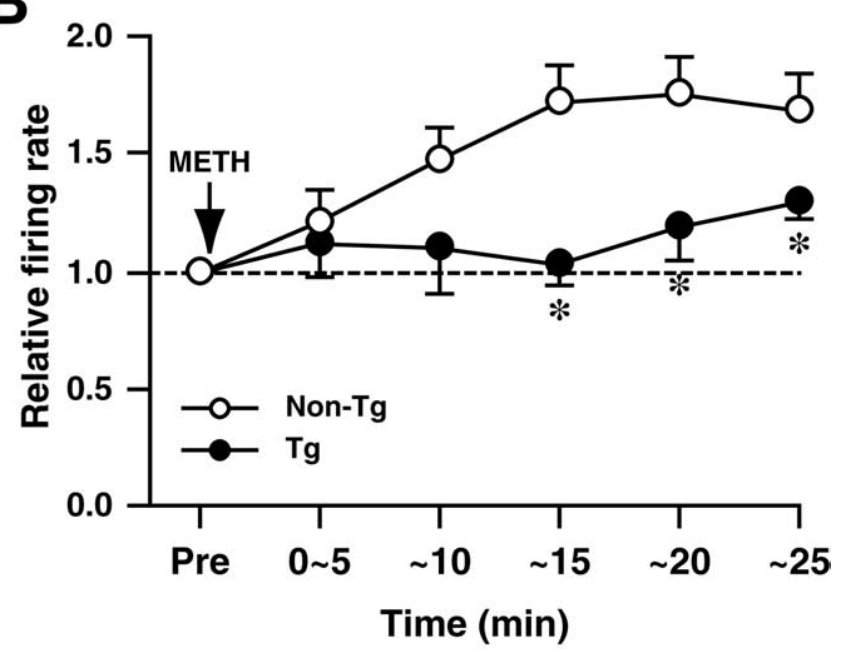

Figure 8. STN elimination blocks METH-induced elevation of the GP activity. $\boldsymbol{A}$, METHinduced firing of the GP neurons. After recording of spontaneous firing, the mice were administered METH ( $1.0 \mathrm{mg} / \mathrm{kg}$, s.c.), and recording was then performed from the IT-injected side. The firing pattern and digital raster display of representative units during pretreatment (Pre) and 25 min after treatment are shown. The mean firing rate ( $\mathrm{Fr}$; spikes per second) of the unit is presented. $\boldsymbol{B}$, Time course of METH-induced firing rate. The average of firing rate for every $5 \mathrm{~min}$ period was calculated, and the ratio of drug-induced firing rate relative to spontaneous firing rate was plotted $(n=5) .{ }^{*} p<0.05$, significant differences from non- $T g$ mice.

Crutcher, 1990; DeLong, 1990; Parent and Hazrati, 1995; Gerfen and Wilson, 1996).

The shift in the pattern of spontaneous firing of the SNr neurons by STN ablation was characterized by a reduction in the proportion of the regular firing type and an increase in the proportion of the bursty firing type. However, the STN ablation did not influence the shape and cell density of the SNr. These data suggest that STN neurons contribute to the generation of the regularity in spontaneous firing of the output neurons. Previous electrophysiological studies show that the STN neurons possess intrinsic tonic firing activity (Nakanishi et al., 1987; Bergman et al., 1994; Song et al., 2000) and that this activity is generated from different types of subthreshold sodium currents (Bevan and Wilson, 1999; Beurrier et al., 2000; Do and Bean, 2003). The property of spontaneous firing of the STN neurons may be important to determine the firing pattern of the output neurons and thereby may subserve normal movement control.

A previous study reports that excitotoxic lesion of the STN in
Figure 9. Pharmacological blockade of GP inhibits electrophysiological response of output neurons and behavioral susceptibility to METH. $\boldsymbol{A}$, Single-unit recording of the SNr neurons. C57BL/6 inbred mice $(n=6)$ were treated intrapallidally with PBS or NBQX at $125 \mathrm{ng} / \mathrm{site}$, and, $15 \mathrm{~min}$ later, they were administered METH ( $1.0 \mathrm{mg} / \mathrm{kg}$, s.c.) for unit recording. The average of firing rate for every 5 min period was calculated, and the ratio of METH-induced firing rate relative to spontaneous firing rate was plotted. ${ }^{*} p<0.05,{ }^{* *} p<0.01$, significant differences from the PBS-treated group. $B$, Influence of NBQX on c-fos induction in the GP. The inbred mice $(n=4)$ were treated intrapallidally with PBS or NBQX ( $125 \mathrm{ng} /$ site), administered METH (4.0 $\mathrm{mg} / \mathrm{kg}$, s.c.), and, $1 \mathrm{~h}$ later, used for brain sectioning. The sections through the GP were immunostained with anti-c-fos antibody, and the number of c-fos-positive cells in the GP was counted. ${ }^{*} p<0.05$, significant difference from the PBS-treated group. Representative microscopic images are shown, and bottom images are fourfold magnified views of the GP (boxes in the top images). Scale bar, $200 \mu \mathrm{m}$. C, METH-induced locomotion. C57BL/6J inbred mice ( $n=$ 6) were treated intrapallidally with $\mathrm{NBQX}$ at different doses, and, 15 min later, they were administered METH $(4.0 \mathrm{mg} / \mathrm{kg}$, s.c.) for measurement of drug-induced locomotor activity. ${ }^{*} p<0.05$, significant differences from the PBS-treated group.
PBS

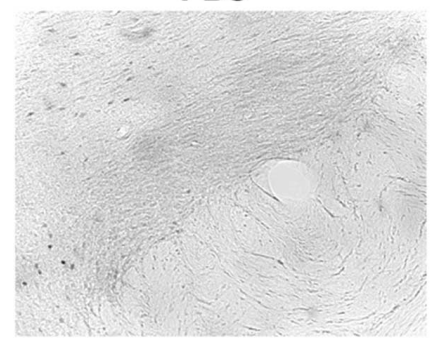

METH

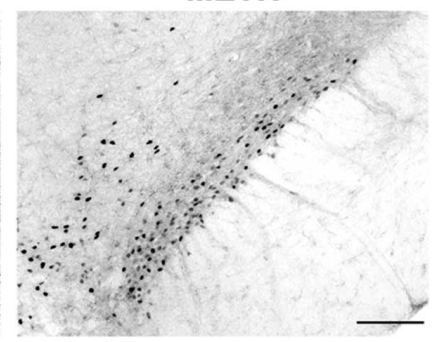

Figure 10. c-Fos induction in the STN after METH administration. C57BL/6J inbred mice were administered PBS or METH ( $4.0 \mathrm{mg} / \mathrm{kg}$, s.c.), and, $1 \mathrm{~h}$ later, they were used for brain sectioning. The sections through the STN were immunostained with anti-c-fos antibody. Scale bar, $100 \mu \mathrm{m}$.

primates causes a reduction in firing activity in the external (GPe) and internal (GPi) segments of the GP (Hamada and DeLong, 1992b). Although in the present study we did not examine the influence of the STN ablation on the firing activity of the EPN neurons, our results suggest a role of the STN neurons in exciting spontaneous firing of the output nuclei in basal ganglia and support the results obtained from primates showing the reduced GPi activity by the STN lesion. In contrast, the STN ablation in this study did not cause any significant changes in the activity of the GP neurons. Another previous study with excitotoxic STN lesion 
in rodents also shows no alterations in the firing rate of the GP in the lesioned animals ( $\mathrm{Ni}$ et al., 2000). Some anatomical and electrophysiological studies indicate that axons of the STN innervate both the GP and SNr through their collaterals in rodents (Kita et al., 1983; Kita and Kitai, 1987; Robledo and Féger, 1990; Nakanishi et al., 1991). In primates, a recent study reports that the majority of the STN axons projects to the GPe and the GPi/SNr with different sets of collaterals innervating some targets (Sato et al., 2000b). Therefore, the difference in the influence of STN lesion on the GP or GPe activity between the aforementioned studies does not appear to be derived from the distinction in the pattern of STN projections between the species. Conversely, primate GPe neurons are divided into two different firing types, termed the high-frequency dischargepause type and the low-frequency discharge-burst type, and the high-frequency discharge-pause cells are predominant (Hamada and DeLong, 1992b). Our unit recording indicated the presence of the bursty and irregular types of GP neurons in mice, and the bursty type was the major proportion. The difference in the firing property of these neurons may affect dependency of their spontaneous firing activity on the STN input.

IMCT of the STN neurons caused a reduction in METHinduced hyperactivity, which was accompanied by attenuation of drug-induced suppression of the SNr firing and blockade of drug-induced elevation of the GP firing (supplemental Fig. $1 C$, available at www.jneurosci.org as supplemental material). These results indicate that the STN neurons mediate $\mathrm{METH}$-induced motor behavior and METH responsiveness of the $\mathrm{SNr}$ and GP neurons. In addition, our histological examination indicated activation of the STN neurons in response to METH administration, being consistent with previous electrophysiological studies (Kreiss et al., 1996, 1997). One explanation for these observations is that the STN activation in response to METH facilitates GP activity through the subthalamopallidal pathway and that this facilitation induces suppression of $\mathrm{SNr}$ activity through the pallidonigral pathway, thereby leading to drug-induced motor activation (supplemental Fig. $1 D$, available at www.jneurosci.org as supplemental material). The facilitation of the pallidonigral pathway may dominate the opposite activity of the subthalamonigral pathway to suppress the net activity of SNr neurons. Partial suppression of $\mathrm{SNr}$ activity under the cell-ablation condition may be derived from facilitation of the striatonigral pathway. Again, the data obtained from the pharmacological blockade of GP activation suggest that the blockade attenuates METHinduced suppression of $\mathrm{SNr}$ activity and in turn diminishes the behavioral response (supplemental Fig. $1 E$, available at www.jneurosci.org as supplemental material), supporting the view that the STN activation contributes to drug-induced regulation of the output activity and the motor behavior mainly through the subthalamo-pallido-nigral pathway.

One possible mechanism by which the GP-mediated pathways dominate the subthalamonigral pathway in DA-induced motor behavior involves the property and distribution of synaptic terminals originating from the GP or the STN on the output neurons. The GP terminals are known to form symmetrical synaptic contacts with large boutons that distribute densely in the perikarya and proximal dendrites of the output neurons (Smith and Bolam, 1991; Bolam and Smith, 1992; Smith et al., 1998), whereas the STN terminals appear to make asymmetrical synaptic contacts with relatively smaller boutons that show a scattered distribution over the perikarya and dendrites of these neurons (Bevan et al., 1994; Smith et al., 1998). The facilitation of the GP neurons, because of their synaptic property and distribution, may produce a greater effect of GABAergic inhibition on the output neurons, shunting the glutamatergic excitation through the subthalamonigral pathway.

There are two potential mechanisms by which systemic administration of METH induces hyperactivity of the STN neurons. One is the activation of the cortical neurons in response to DA, which then stimulates the STN neurons through the direct corticosubthalamic route. Administration of DA receptor agonists is known to activate many neurons in the cortical areas that are innervated by midbrain DA neurons (Wang et al., 1995). Indeed, electrical stimulation of the cortical neurons increases the discharge of the STN neurons (Nambu et al., 2000). Another mechanism is the direct activation of the STN neurons by DA. These neurons receive direct inputs from midbrain DA neurons (Hassani et al., 1997), and DA receptor agonists alter the discharge of the STN neurons (Mintz et al., 1986; Baufreton et al., 2003). It remains to be determined which mechanism is involved in the activation of the STN neurons in response to systemic DA stimulation.

A selective loss of the nigrostriatal DA system in Parkinson's disease is reported to cause hyperactivity of the STN neurons (Bergman et al., 1994; Hassani et al., 1996; Magnin et al., 2000). This hyperactivity is considered to be derived from the decreased GP activity because of the loss of DA function and appears to be linked to the symptoms of the disease. Our results obtained from the analysis of the neural circuitry underlying DA-induced motor behavior indicate that activation of the STN neurons results in the facilitation of GP activity. Comparison of these facts suggests that the STN activation affects motor behavior depending on the state of neural activity of other basal ganglia nuclei.

In conclusion, our findings demonstrate that the STN neurons are involved in dual regulation of basal ganglia function through differential neural pathways dependent on the state of DA transmission. The STN neurons function to suppress spontaneous motor behavior by facilitating the output neurons mainly through the subthalamonigral pathway. In response to DA stimulation, an increase in the STN activity contributes to the expression of motor behavior by inducing suppression of the output neurons, in particular through the subthalamo-pallidonigral pathway. Detailed understanding of the cellular mechanisms for differential control of the neural circuitry through the STN will provide the physiological basis of various motor functions and the clinical evidence for therapeutic approaches to movement disorders.

\section{References}

Alexander GE, Crutcher MD (1990) Functional architecture of basal ganglia circuits: neural substrates of parallel processing. Trends Neurosci 13:266-271.

Baufreton J, Garret M, Rivera A, de la Calle A, Gonon F, Dufy B, Bioulac B, Taupignon A (2003) $D_{5}$ (not $D_{1}$ ) dopamine receptors potentiate burstfiring in neurons of the subthalamic nucleus by modulating an L-type calcium conductance. J Neurosci 23:816-825.

Baunez C, Robbins TW (1997) Bilateral lesions of the subthalamic nucleus induce multiple deficits in an attentional task in rats. Eur J Neurosci 9:2086-2099.

Baunez C, Nieoullon A, Amalric M (1995) In a rat model of parkinsonism, lesions of the subthalamic nucleus reverse increases of reaction time but induce a dramatic premature responding deficit. J Neurosci 15:6531-6541.

Baunez C, Amalric M, Robbins TW (2002) Enhanced food-related motivation after bilateral lesions of the subthalamic nucleus. J Neurosci 22:562-568.

Benazzouz A, Gross C, Féger J, Boraud T, Bioulac B (1993) Reversal of rigidity and improvement in motor performance by subthalamic highfrequency stimulation in MPTP-treated monkeys. Eur J Neurosci 5:382-389. 
Bergman H, Witchmann T, DeLong MR (1990) Reversal of experimental parkinsonism by lesions of the subthalamic nucleus. Science 249:1436-1438.

Bergman H, Wichmann T, Karmon B, DeLong MR (1994) The primate subthalamic nucleus. II. Neuronal activity in the MPTP model of parkinsonism. J Neurophysiol 72:507-520.

Beurrier C, Bioulac B, Hammond C (2000) Slowly inactivating sodium current $\left(I_{\mathrm{NaP}}\right)$ underlies single-spike activity in rat subthalamic neurons. J Neurophysiol 83:1951-1957.

Bevan MD, Wilson CJ (1999) Mechanisms underlying spontaneous oscillation and rhythmic firing in rat subthalamic neurons. J Neurosci 19:7617-7628.

Bevan MD, Bolam JP, Crossman AR (1994) Convergent synaptic input from the neostriatum and the subthalamus onto identified nigrothalamic neurons in the rat. Eur J Neurosci 6:320-334.

Bevan MD, Clarke NP, Bolam JP (1997) Synaptic integration of functionally diverse pallidal information in the entopeduncular nucleus and subthalamic nucleus in the rat. J Neurosci 17:308-324.

Bevan MD, Magill PJ, Terman D, Bolam JP, Wilson CJ (2002) Move to the rhythm: oscillations in the subthalamic nucleus-external globus pallidus network. Trends Neurosci 25:525-531.

Bolam JP, Smith Y (1992) The striatum and the globus pallidus send convergent synaptic inputs onto single cells in the entopeduncular nucleus of the rat: a double anterograde labeling study combined with postembedding immunocytochemistry for GABA. J Comp Neurol 321:456-476.

Burbaud P, Gross C, Benazzouz A, Coussemacq M, Bioulac B (1995) Reduction of apomorphine-induced rotational behaviour by subthalamic lesion in 6-OHDA lesioned rats is associated with a normalization of firing rate and discharge pattern of pars reticulata neurons. Exp Brain Res 105:48-58.

Cenci MA, Kalén P, Mandel RJ, Wictorin K, Björklund A (1992) Dopaminergic transplants normalize amphetamine- and apomorphine-induced Fos expression in the 6-hydroxydopamine-lesioned striatum. Neuroscience 46:943-957.

DeLong MR (1990) Primate models of movement disorders of basal ganglia origin. Trends Neurosci 13:281-285.

Do MTH, Bean BP (2003) Subthreshold sodium currents and pacemaking of subthalamic neurons: modulation by slow inactivation. Neuron 39:109-120.

Dybdal D, Gale K (2000) Postural and anticonvulsant effects of inhibition of the rat subthalamic nucleus. J Neurosci 20:6728-6733.

Gerfen CR, Wilson CJ (1996) The basal ganglia. In: Handbook of chemical anatomy, Vol 12 (Swanson LW, Björklund A, Hökfelt T, eds), pp 37-468. Amsterdam: Elsevier.

Gulley JM, Kuwajima M, Mayhill E, Rebec GV (1999) Behavior-related changes in the activity of substantia nigra pars reticulata neurons in freely moving rats. Brain Res 845:68-76.

Hamada I, DeLong MR (1992a) Excitotoxic acid lesions of the primate subthalamic nucleus result in transient dyskinesias of the contralateral limbs. J Neurophysiol 68:1850-1858.

Hamada I, DeLong MR (1992b) Excitotoxic acid lesions of the primate subthalamic nucleus result in reduced pallidal neuronal activity during active holding. J Neurophysiol 68:1859-1866.

Hassani O-K, Mouroux M, Féger J (1996) Increased subthalamic neuronal activity after nigral dopminergic lesion independent of disinhibition via the globus pallidus. Neuroscience 72:105-115.

Hassani O-K, Francois C, Yelnik J, Féger J (1997) Evidence for a dopaminergic innervation of the subthalamic nucleus in the rat. Brain Res 749:88-94.

Hirata A, Yoshida S, Inoue N, Matsumoto-Miyata K, Ninomiya A, Taniguchi M, Matsuyama T, Kato K, Iizasa H, Kataoka Y, Yoshida N, Shiosaka S (2001) Abnormalities of synapses and neurons in the hippocampus of neuropsin-deficient mice. Mol Cell Neurosci 17:600-610.

Kaneoke Y, Vitek JL (1996) Burst and oscillation as disparate neuronal properties. J Neurosci Methods 68:211-223.

Kita H, Kitai ST (1987) Efferent projections of the subthalamic nucleus in the rat: light and electron microscopic analysis with the PHA-L method. J Comp Neurol 260:435-452.

Kita H, Chang HT, Kitai ST (1983) The morphology of intracellularly labeled rat subthalamic neurons: a light microscopic analysis. J Comp Neurol 215:245-257.
Kobayashi K, Sasaoka T, Morita S, Nagatsu I, Iguchi A, Kurosawa Y, Fujita K, Nomura T, Kimura M, Katsuki M, Nagatsu T (1992) Genetic alteration of catecholamine specificity. Proc Natl Acad Sci USA 89:1631-1635.

Kobayashi K, Morita S, Mizuguchi T, Sawada H, Yamada K, Nagatsu I, Fujita K, Nagatsu T (1994) Functional and high level expression of human dopamine $\beta$-hydroxylase in transgenic mice. J Biol Chem 269:29725-29731.

Kobayashi K, Morita S, Sawada H, Mizuguchi T, Yamada K, Nagatsu I, Fujita K, Kreitman RJ, Pastan I, Nagatsu T (1995) Immunotoxin-mediated conditional disruption of specific neurons in transgenic mice. Proc Natl Acad Sci USA 92:1132-1136.

Koyama Y, Takahashi K, Kodama T, Kayama Y (2003) State-dependent activity of neurons in the perifornical hypothalamic area during sleep and waking. Neuroscience 119:1209-1219.

Kreiss DS, Anderson LA, Walters JR (1996) Apomorphine and dopamine $D_{1}$ receptor agonists increase the firing rates of subthalamic nucleus neurons. Neuroscience 72:863-876.

Kreiss DS, Mastropietro CW, Rawji SS, Walters JR (1997) The response of subthalamic nucleus neurons to dopamine receptor stimulation in a rat model of Parkinson's disease. J Neurosci 17:6807-6819.

Kreitman RJ, Bailon P, Chaudhary VK, FitzGerald DJ, Pastan I (1994) Recombinant immunotoxins containing anti-Tac(Fv) and derivatives of Pseudomonas exotoxin produce complete regression in mice of an interleukin-2 receptor-bearing human carcinoma. Blood 83:426-434.

Levy R, Hutchison WD, Lozano AM, Dostrovsky JO (2000) High-frequency synchronization of neuronal activity in the subthalamic nucleus of parkinsonian patients with limb tremor. J Neurosci 20:7766-7775.

Limousin P, Pollak P, Benazzouz A, Hoffmann D, Le Bas J-F, Broussolle E, Perret JE, Benabid A-L (1995) Effect on parkinsonian signs and symptoms of bilateral subthalamic nucleus stimulation. Lancet 345:91-95.

Magnin M, Morel A, Jeanmonod D (2000) Single-unit analysis of the pallidum, thalamus and subthalamic nucleus in parkinsonian patients. Neuroscience 96:549-564.

Maurice N, Deniau J-M, Glowinski J, Thierry A-M (1998) Relationships between the prefrontal cortex and the basal ganglia in the rat: physiology of the corticosubthalamic circuits. J Neurosci 18:9539-9546.

Mintz I, Hammond C, Féger J (1986) Excitatory effect of iontophoretically applied dopamine on identified neurons of the rat subthalamic nucleus. Brain Res 375:172-175.

Murer MG, Riquelme LA, Tseng KY, Pazo JH (1997) Substantia nigra pars reticulata single unit activity in normal and 6OHDA-lesioned rats: effects of intrastriatal apomorphine and subthalamic lesions. Synapse $27: 278-293$.

Nakanishi H, Kita H, Kitai ST (1987) Electrical membrane properties of rat subthalamic neurons in an in vitro slice preparation. Brain Res 437:35-44.

Nakanishi H, Kita H, Kitai ST (1991) Intracellular study of rat entopeduncular nucleus neurons in an in vitro slice preparation: response to subthalamic stimulation. Brain Res 549:285-291.

Nambu A, Tokuno H, Hamada I, Kita H, Imanishi M, Akazawa T, Ikeuchi Y, Hasegawa N (2000) Excitatory cortical inputs to pallidal neurons via the subthalamic nucleus in the monkey. J Neurophysiol 84:289-300.

Ni Z, Bouali-Benazzouz R, Gao D, Benabid A-L, Benazzouz A (2000) Changes in the firing pattern of globus pallidus neurons after the degeneration of nigrostriatal pathway are mediated by the subthalamic nucleus in the rat. Eur J Neurosci 12:4338-4344.

Nishii K, Matsushita N, Sawada H, Sano H, Noda Y, Mamiya T, Nabeshima T, Nagatsu I, Hata T, Kiuchi K, Yoshizato H, Nakashima K, Nagatsu T, Kobayashi K (1998) Motor and learning dysfunction during postnatal development in mice defective in dopamine neuronal transmission. J Neurosci Res 54:450-464.

Parent A, Hazrati L-N (1995) Functional anatomy of the basal ganglia. I. The cortico-basal ganglia-thalamo-cortical loop. Brain Res Brain Res Rev 20:91-127.

Paxinos G, Franklin KBJ (2001) The mouse brain in stereotaxic coordinates, Ed 2. San Diego: Academic.

Plenz D, Kitai ST (1999) A basal ganglia pacemaker formed by the subthalamic nucleus and external globus pallidus. Nature 400:677-682.

Robledo P, Féger J (1990) Excitatory influence of rat subthalamic nucleus to substantia nigra pars reticulata and the pallidal complex: electrophysiological data. Brain Res 518:47-54. 
Ruskin DN, Marshall JF (1995) D1 dopamine receptors influence Fos immunoreactivity in the globus pallidus and subthalamic nucleus of intact and nigrostriatal-lesioned rats. Brain Res 703:156-164.

Sano H, Yasoshima Y, Matsushita N, Kaneko T, Kohno K, Pastan I, Kobayashi K (2003) Conditional ablation of striatal neuronal types containing dopamine $\mathrm{D}_{2}$ receptor disturbs coordination of basal ganglia function. J Neurosci 23:9078-9088.

Sato F, Lavallée P, Lévesque M, Parent A (2000a) Single-axon tracing study of neurons of the external segment of the globus pallidus in primate. J Comp Neurol 417:17-31.

Sato F, Parent M, Levesque M, Parent A (2000b) Axonal branching pattern of neurons of the subthalamic nucleus in primates. J Comp Neurol 424:142-152.

Smith Y, Bolam JP (1991) Convergence of synaptic inputs from the striatum and the globus pallidus onto identified nigrocollicular cells in the rat: a double anterograde labelling study. Neuroscience 44:45-73.

Smith Y, Bolam JP, von Krosigk M (1990) Topographical and synaptic organization of the GABA-containing pallidosubthalamic projection in the rat. Eur J Neurosci 2:500-511.
Smith Y, Bevan MD, Shink E, Bolam JP (1998) Microcircuitry of the direct and indirect pathways of the basal ganglia. Neuroscience 86:353-387.

Song W-J, Baba Y, Otsuka T, Murakami F (2000) Characterization of $\mathrm{Ca}^{2+}$ channels in rat subthalamic nucleus neurons. J Neurophysiol 84:2630-2637.

Wang JQ, Smith AJW, McGinty JF (1995) A single injection of amphetamine or methamphetamine induces dynamic alterations in c-fos, zif/268 and preprodynorphin messenger RNA expression in rat forebrain. Neuroscience 68:83-95.

Watanabe D, Inokawa H, Hashimoto K, Suzuki N, Kano M, Shigemoto R, Hirano T, Toyama K, Kaneko S, Yokoi M, Moriyoshi K, Suzuki M, Kobayashi K, Nagatsu T, Pastan I, Nakanishi S (1998) Ablation of cerebellar Golgi cells disrupts synaptic integration involving GABA inhibition and NMDA receptor activation in motor coordination. Cell 95:17-27.

Witchmann T, Bergman H, DeLong MR (1994) The primate subthalamic nucleus. III. Changes in motor behavior and neuronal activity in the internal pallidum induced by subthalamic inactivation in the MPTP model of Parkinsonism. J Neurophysiol 72:521-530.

Zhang X-X, Zhu Z-T, Jin G-Z (1998) Comparison of (-)-stepholidine and $\mathrm{D}_{1}$ or $\mathrm{D}_{2}$ agonists on unit firing of globus pallidus in 6-hydroxydopaminelesioned rats. Life Sci 63:537-544. 